\title{
Avaliação de balanço anual de cátions e ânions na bacia do Alto Sorocaba (SP)
}

\author{
Diego de Souza Sardinha ${ }^{1}$, Fabiano Tomazini da Conceição ${ }^{2}$, Daniel Marcos Bonotto ${ }^{1}$, Mauro \\ Henrique Dourador de Salles ${ }^{2}$ \& Vivian Andréa Angelucci ${ }^{2}$
}

\begin{abstract}
Resumo Este trabalho avaliou o balanço anual de cátions e ânions na bacia do Alto Sorocaba, indicando como as influências antropogênicas estão afetando esses valores. Oito pontos de amostragem foram estabelecidos e realizaram-se seis amostragens em 13/08/06, 20/09/06, 18/10/06, 23/11/06, 10/12/06 e 10/01/07, envolvendo o período seco e chuvoso. As análises foram executadas para vazão, temperatura, $\mathrm{pH}$, condutividade, oxigênio dissolvido, sólidos totais dissolvidos e em suspensão, cálcio, magnésio, sódio, potássio, alcalinidade, cloreto, sulfato, fosfato e nitrato. Os resultados indicam que alguns pontos de coleta nos rios de Una (P1), Sorocabuçu (P2) e Sorocamirim (P3) possuem características mais próximas ao comportamento natural de cátions e ânions dissolvidos devido ao intemperismo das rochas. No entanto, a ausência de tratamento para os efluentes domésticos na cidade de Ibiúna e as intensas atividades agrícolas reduzem a qualidade da água após estes pontos, aumentando o processo de eutrofização no Reservatório de Itupararanga.
\end{abstract}

Palavras-chave: bacia hidrográfica, interação água-rocha/solo, influências antropogênicas, gerenciamento ambiental.

\begin{abstract}
Annual balance evaluation of cations and anions at Alto Sorocaba basin (SP). This work evaluated the annual balance of cations and anions at Alto Sorocaba basin, indicating how anthropogenic influences are affecting these values. Eight sampling points were established and it was realized six field campaigns in 08/13/06,09/20/06, 10/18/06, 11/23/06, 12/10/06 and 01/10/07, that involved the dry and wet period. The analyses were executed for discharge, temperature, $\mathrm{pH}$, conductivity, dissolved oxygen, total dissolved and suspended solids, calcium, magnesium, sodium, potassium, alkalinity, chloride, sulfate, phosphate and nitrate. The results indicated that some points at the Una (P1), Sorocabuçu (P2) and Sorocamirim (P3) rivers possess characteristics closer to the natural behavior of dissolved cations and anions in waters due to the weathering of the rocks. However, the absence of treatment of domestic waste at Ibiúna city and the strong agricultural activities reduced the water quality downstream of these points, increasing the eutrophic process in the Itupararanga Reservoir.
\end{abstract}

Keywords: watershed, water-rock interaction, anthropogenic influences, environmental management.

INTRODUÇÃO Dentre os recursos naturais mais fundamentais, a água é o que possui maior destaque, pois sua disponibilidade é necessária a todo tipo de vida no planeta, bem como para a maioria dos meios de produção. A disponibilidade de água significa que ela estará presente não somente em quantidade, mas também que sua qualidade seja satisfatória para suprir as necessidades de um determinado conjunto de seres vivos (biota), podendo ainda ser utilizada para gerar energia elétrica, assimilar resíduos e uma variedade de outros propósitos (Porto, 1991). O uso da água pelo ser humano para qualquer finalidade resulta na deterioração da sua qualidade, limitando geralmente seu potencial de uso (Meybeck et al., 1996).

A expressão corrente "qualidade da água" não se refere a um grau de pureza absoluto ou mesmo próximo disto, mas sim a um padrão tão próximo quanto possível do "natural", isto é, como a água se encontra nos rios e nascentes, antes do contato com o Homem.
Além disso, há um grau de pureza desejável para a água, o qual depende do uso que dela será feito, incluindo-se mudanças hidrológicas, tais como seu armazenamento nos reservatórios ou sua transferência de uma área de drenagem à outra (Branco, 1991). Os múltiplos usos da água e as permanentes necessidades de água para fazer frente ao crescimento populacional e às demandas industriais e agrícolas têm gerado permanente pressão sobre os recursos hídricos (Tundisi, 2005).

O gerenciamento dos recursos hídricos é um conjunto de ações que garante às populações e às atividades econômicas uma utilização otimizada da água, tanto em termos qualitativos como quantitativos. Considerando-se a complexa dependência dos processos relacionados ao ciclo hidrológico, disponibilidade, uso da água e interações com a saúde humana, o manejo integrado deste recurso natural deve apoiar-se nas bases bio-geo-físicas do sistema, representadas pelas unidades naturais que são as bacias hidrográficas (Souza \& 
Tundisi, 2000). Assim, cada bacia hidrográfica deve ter um plano de utilização integrada de recursos hídricos, o qual deve constituir o referencial de todas as decisões e intervenções setoriais nestes recursos (Mota, 1997).

Contudo, poucos estudos são realizados associando-se a influência das águas de chuva no fluxo anual de cátions e ânions em bacias hidrográficas (Conceição \& Bonotto, 2004). As espécies dissolvidas contidas nas águas pluviais (deposição seca e úmida) podem ser divididas em três grupos: (a) derivados de aerossóis marinhos; (b) derivados de aerossóis terrestres (poeira de solo e emissões biológicas), e (c) derivados de fontes antrópicas (Négrel \& Roy, 1998). A alteração no sistema aquático provocado pelas águas pluviais interfere diretamente na trofia deste sistema, promovendo vários efeitos em níveis de saúde, biológicos, econômicos e sociais (Conceição \& Bonotto, 2002; Souza \& Tundisi, 2003; Conceição et al., 2007).

A alteração no sistema aquático provocado por ações antrópicas interfere diretamente na trofia do sistema aquático, promovendo vários efeitos em níveis de saúde, biológicos, econômicos e sociais (Conceição \& Bonotto, 2002; Souza \& Tundisi, 2003; Conceição et al., 2007). As principais drenagens formadoras da bacia do Alto Sorocaba no Estado de São Paulo são os rios de Una, Sorocabuçu, Sorocamirim que formam o Rio Sorocaba pouco antes do Reservatório de Itupararanga, importante manancial que abastece cerca de 1.000 .000 pessoas nos municípios de Ibiúna, Sorocaba, Mairinque e Votorantim. Assim, este trabalho tem como principal objetivo proceder à avaliação de balanço anual de cátions e ânions, visando determinar a contribuição natural de cada sub-bacia para as águas superficiais. Além disso, pretende-se sugerir como as influências antropo- gênicas estão afetando esses valores, de maneira a auxiliar no conhecimento dos ecossistemas aquáticos da bacia do Alto Sorocaba e no fornecimento de subsídios para o seu desenvolvimento sustentável.

CARACTERIZAÇÃO DA ÁREA DE ESTUDO A bacia do Alto Sorocaba é uma das seis sub-bacias que compõem a bacia do Sorocaba Médio Tietê(SMT), possuindo área de aproximadamente $929 \mathrm{~km}^{2} \mathrm{e}$ situando-se na porção sudeste do Estado de São Paulo, mais precisamente entre os paralelos $23^{\circ} 45^{\prime} 37^{\prime \prime}$ e $23^{\circ} 35^{\prime} 02^{\prime \prime} \mathrm{de}$ latitude S e $47^{\circ} 21^{\prime} 00^{\prime \prime}$ e $46^{\circ} 57^{\prime} 29^{\prime \prime}$ de longitude W. Esta bacia é formada pelos rios de Una, Sorocabuçu e Sorocamirim, cujas cabeceiras se encontram nos município de Ibiúna, Cotia, Vargem Grande Paulista e São Roque, e formam o Rio Sorocaba (Fig. 1).

A população total da bacia do Alto Sorocaba é de 110.577 habitantes, sendo Alumínio, Cotia, Ibiúna, Mairinque, Piedade, São Roque, Vargem Grande Paulista e Votorantim os municípios que a compõe. A área urbanizada na bacia do Alto Sorocaba ocupa por volta de $71 \mathrm{~km}^{2}$, sendo cerca de $55 \mathrm{~km}^{2}$ caracterizada por pequenos aglomerados populacionais como vilas e vilarejos. Com uma intensa atividade agrícola, esta bacia possui $393 \mathrm{~km}^{2}$ ocupados por culturas olerícolas, seguidos da batata e do tomate. Quanto à cobertura vegetal, a bacia é composta por floresta ombrófila densa e cerrado, estando inserida no domínio da Mata Atlântica.

A bacia do Alto Sorocaba apresenta clima Cwb, ou seja, clima úmido quente com inverno seco. A temperatura média anual é de $20^{\circ} \mathrm{C}$ e no semestre seco a evaporação é maior que a precipitação. A precipitação média anual entre os anos de 1960 e 2004 foi de $1.492,7 \mathrm{~mm}$, sendo janeiro o mês mais chuvoso (média de $248,1 \mathrm{~mm}$ )

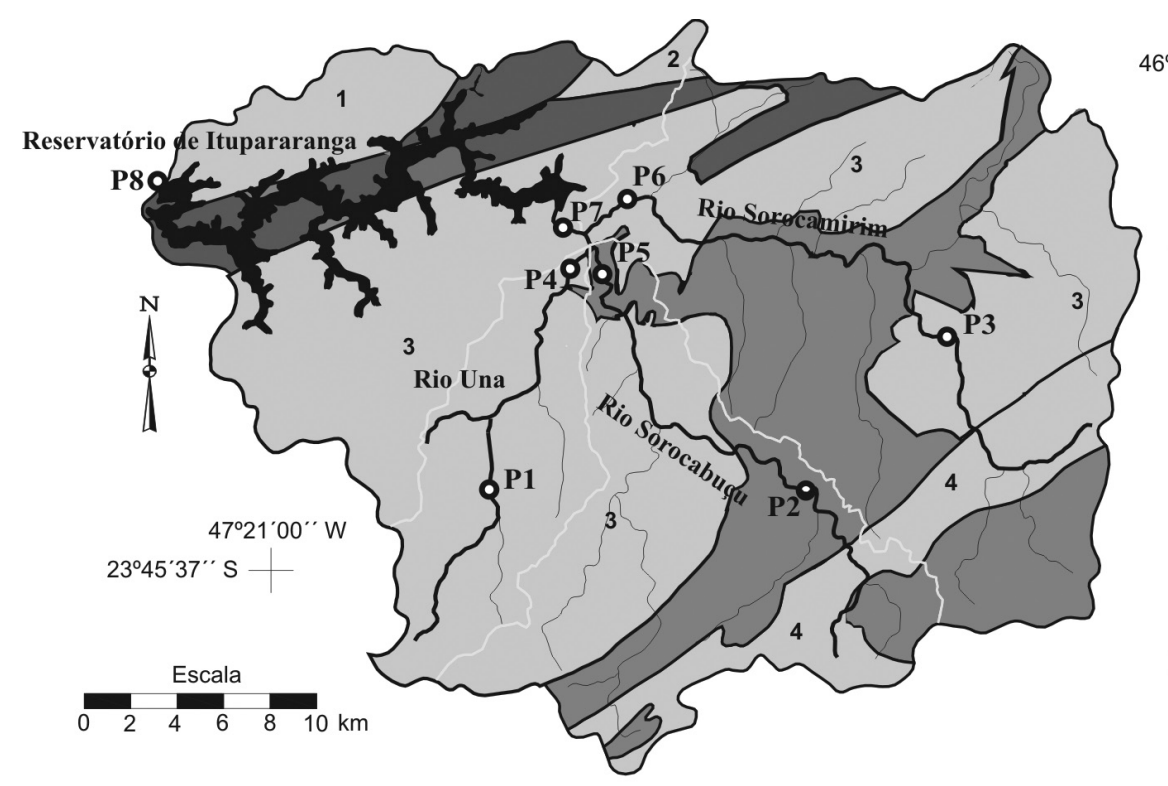

$46^{\circ} 57^{\prime} 29^{\prime \prime} \mathrm{W}$
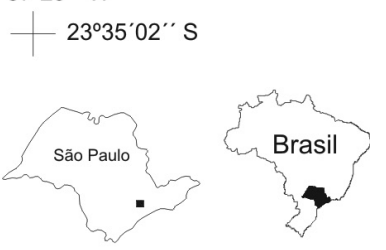

\section{Legenda}

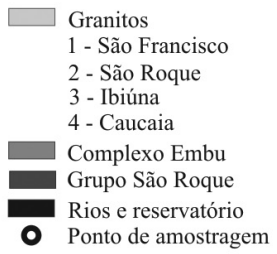

Figura 1 - Mapa de localização e geológico, com os pontos de coleta de água fluviais, na bacia do Alto Sorocaba (modificado de IPT, 2005). P1 e P4 = Rio de Una, P2 e P5 = Rio Sorocabuçu, P3 e P6 = Rio Sorocamirim e P7 e P8 = Rio Sorocaba. 
e agosto o mês mais seco (média de 42,8 mm) (CBA, 2006). Em relação às vazões afluentes no Reservatório de Itupararanga (Rio Sorocaba), os meses com maior e menor vazão média afluente são fevereiro $\operatorname{com} 21,7 \mathrm{~m}^{3} / \mathrm{s}$ e agosto com $6,9 \mathrm{~m}^{3} / \mathrm{s}$, respectivamente (CBA, 2006). A figura 2 apresenta a precipitação média mensal (a) e a vazão média mensal afluente ao Reservatório de Itupararanga (b), podendo notar que o regime do Rio Sorocaba é diretamente proporcional à precipitação.

A bacia do Alto Sorocaba é composta por diversas estruturas geológicas, com período de formação desde o Proterozóico Médio-Superior até o Quaternário, destacando-se os domínios São Roque e o Embu (Fig. 1). O Domínio São Roque apresenta rochas de baixo grau metamórfico do Grupo São Roque (filitos e meta-básicas) (Godoy et al., 1996a) e complexos granitóides associados, tais como os granitos São Francisco (sienogranitos e monzogranitos) e São Roque (dioritos e granodioritos) (Godoy, 1989; Godoy \& Figueiredo, 1991; Hackspacher et al., 1991). No Domínio Embu predominam paragnaisses e migmatitos do Complexo Embu, ocorrendo também a presença dos granitos Ibiúna (monzogranitos e sienogranitos) e Caucaia (monzogranitos e sienogranitos) (Godoy et al., 1996b). Em relação aos solos, a bacia do Alto Sorocaba apresenta três tipos de classes de solos, ou seja, Argissolos, Latossolos e Cambissolos (IPT, 2005).

MATERIAIS E MÉTODOS Para avaliar a composição química das águas superficiais na bacia do Alto Sorocaba, foram realizadas seis coletas de amostras: 13/08/2006, 20/09/2006, 18/10/2006, 23/11/2006, $19 / 12 / 2006$ e 10/01/2007. Esse período abrange extrema variação de vazão nos rios da bacia do Alto Sorocaba. A seguinte convenção para os pontos de coleta (Fig. 1), será utilizada durante o desenvolvimento deste trabalho: P1 e P4 (Rio de Una), P2 e P5 (Rio Sorocabuçu), P3 e P6 (Rio Sorocamirim) e P7 e P8 (Rio Sorocaba).

As medidas de condutividade elétrica $(\mu \mathrm{S} /$ $\mathrm{cm})$, temperatura da água $\left({ }^{\circ} \mathrm{C}\right)$, potencial hidrogeniônico $(\mathrm{pH})$ e oxigênio dissolvido $(\mathrm{mg} / \mathrm{L})$ foram realizadas com equipamentos de leitura direta no próprio local de amostragem (YSI, modelo YSI 100). Com a ajuda de frascos de polietileno, previamente lavados com água destilada e enxaguados no campo com a água coletada, as amostras foram acondicionadas e levadas ao Laboratório de Geoquímica Ambiental do Departamento de Engenharia Ambiental da UNESP de Sorocaba (SP), onde foram analisados os seguintes parâmetros químicos: alcalinidade, sulfato, fosfato e nitrato. Amostras de água conservadas com $\mathrm{HNO}_{3}(\mathrm{pH}>2)$ também foram quantificadas em sódio, potássio, cálcio e magnésio neste laboratório, sendo a alíquota remanescente posteriormente transportada para o Laboratório de Isótopos e Hidroquímica (LABIDRO) do Departamento de Petrologia e Metalogenia (DPM) do IGCE da UNESP de Rio Claro (SP), onde se analisaram os teores de cloreto, sólidos totais dissolvidos e sólidos totais suspensos.

A alcalinidade foi determinada pela titulação
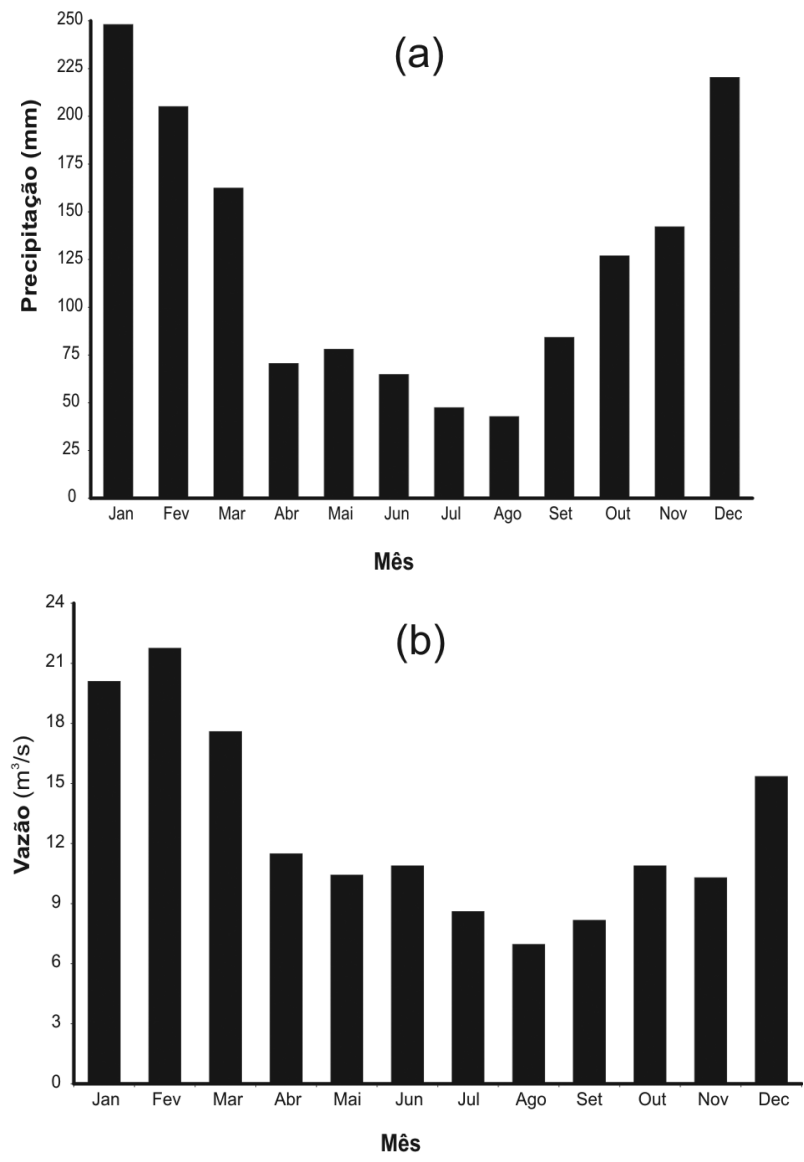

Figura 2 - Precipitação e vazão médias na bacia do Alto Sorocaba. (a) Precipitação média mensal $(\mathrm{mm})$ e (b) vazão afluente $\left(\mathrm{m}^{3} / \mathrm{s}\right)$ do Reservatório de Itupararanga entre os anos de 1960 e 2004 na bacia do Alto Sorocaba (CBA, 2006).

com ácido sulfúrico $0,01 \mathrm{~N}$ com concentração entre 1 e $500 \pm 0,2 \mathrm{mg} / \mathrm{L}$ (Standard Methods, 1999). Sulfato (método turbidimétrico de sulfato de bário, de 0 a $70 \pm$ $0,9 \mathrm{mg} / \mathrm{L}$ ), fosfato (método do ácido ascórbico, de 0 a 3 $\pm 0,01 \mathrm{mg} / \mathrm{L}$ ) e nitrato (método de redução de cádmio, de 0 a $30 \pm 0,8 \mathrm{mg} / \mathrm{L}$ ) foram quantificados por espectrofotômetro DR 2800 da Hach Company (Hach, 1992). Sódio, potássio, cálcio e magnésio foram quantificados por espectrometria de absorção atômica (AAS - Varion 240-FS). Cloreto, utilizou-se o método potenciométrico $(0,1$ a $100 \pm 0,02 \mathrm{mg} / \mathrm{L})$, empregando-se um eletrodo íon-sensível Orion modelo $94-17 B$ e um eletrodo de referência Orion modelo 90-02 (junção dupla) e o analisador Analion modelo IA-601. Sólidos totais dissolvidos e sólidos totais suspensos foram quantificados por métodos gravimétricos (Standard Methods, 1999).

A vazão em todos os pontos de coleta foi quantificada segundo a metodologia descrita por Hermes \& Silva (2004), utilizando-se uma trena, um objeto flutuador e um cronômetro, sendo as variáveis colocadas posteriormente na equação 1 .

$$
Q=\frac{A \cdot D \cdot C}{T}
$$


Onde:

$Q=$ vazão $\left(\mathrm{m}^{3} / \mathrm{s}\right) ; A=$ área da seção transversal do rio $\left(\mathrm{m}^{2}\right) ; D=$ distância usada para medir a velocidade do rio $(\mathrm{m}) ; C=$ coeficiente de correção $(0,9$ para rios com fundo lodoso); $T=$ tempo (s) gasto pelo objeto flutuador para atravessar a distância D.

\section{RESULTADOS}

Parâmetros físico-químicos Nas tabelas 1 e 2 constam os resultados obtidos para os parâmetros determinados nas águas fluviais da bacia do Alto Sorocaba durante os períodos seco e chuvoso.

Conforme esperado, os valores apresentados nas tabelas 1 e 2 confirmaram que as vazões medidas em todos os pontos da amostragem são mais elevadas no mês de janeiro em relação aos demais meses de coleta. Além disso, eles ainda reforçam um outro importante papel do Reservatório de Itupararanga, que é a manutenção do regime hidráulico do Rio Sorocaba a jusante deste reservatório, visto que a vazão de seu exutório variou pouco em todos os meses de coleta.

No ponto P4 há um aumento da condutividade elétrica na época chuvosa. Os menores valores de condutividade elétrica geralmente foram obtidos no Rio
Sorocabuçu (P2). Os maiores valores de condutividade foram caracterizados sempre no Rio de Una (P4), logo após a cidade de Ibiúna, valores que estão acima do limite superior esperado para águas naturais, que é de $100 \mu \mathrm{S} / \mathrm{cm}$ (Hermes \& Silva, 2004). Apesar de que o intemperismo pode elevar a condutividade, acredita-se que os valores mais acentuados devem ser atribuídos principalmente a descargas de efluentes da cidade de Ibiúna e às atividades agrícolas realizadas na sub-bacia do Rio de Una. No ponto P7, os valores de condutividade já se apresentam menores devido à contribuição de águas dos Rios Sorocabuçu e Sorocamirim.

Aumentos na temperatura da água podem estar relacionados com a transferência de calor por radiação, condução e convecção (atmosfera e solo) ou por atividades antrópicas, tais como, despejos de efluentes industriais e domésticos (Espíndola et al., 2000). Dentre os pontos estudados, o valor máximo de temperatura da água foi registrado no Rio Sorocamirim, no ponto P6 no dia $19 / 12 / 2006\left(31,3^{\circ} \mathrm{C}\right)$, sendo o menor valor obtido no Rio de Una, no ponto $\mathrm{P} 4\left(16,9^{\circ} \mathrm{C}\right)$ no dia 13/08/2006. Em geral, há uma variação sazonal de temperatura média para as águas fluviais da bacia do Alto Sorocaba de aproximadamente $4^{\circ} \mathrm{C}$ entre os meses de

Tabela 1 - Parâmetros físico-químicos e químicos na bacia do Alto Sorocaba durante o período seco. P1 e P4 = Rio de Una, P2 e P5 = Rio Sorocabuçu, P3 e P6 = Rio Sorocamirim e P7 e P8 = Rio Sorocaba.

\begin{tabular}{|c|c|c|c|c|c|c|c|c|c|c|c|c|c|c|c|c|}
\hline \multirow{2}{*}{$\begin{array}{c}\text { Ponto } \\
\text { de } \\
\text { coleta }\end{array}$} & \multirow{2}{*}{$\begin{array}{l}\text { Vazão } \\
\left(\mathrm{m}^{3} / \mathrm{s}\right)\end{array}$} & \multirow{2}{*}{$\begin{array}{l}\text { Cond, } \\
(\mu \mathrm{S} / \mathrm{cm})\end{array}$} & \multirow{2}{*}{$\begin{array}{l}\text { Temp } \\
\left({ }^{\circ} \mathrm{C}\right)\end{array}$} & \multirow{2}{*}{$\mathrm{pH}$} & OD & STD & STS & $\mathrm{Ca}^{2+}$ & $\mathrm{Mg}^{2+}$ & $\mathrm{Na}^{+}$ & $\mathrm{K}^{+}$ & $\mathrm{HCO}_{3}^{-}$ & $\mathrm{Cl}^{-}$ & $\mathrm{PO}_{4}{ }^{3-}$ & $\mathrm{SO}_{4}^{2-}$ & $\mathrm{NO}_{3}^{-}$ \\
\hline & & & & & \multicolumn{12}{|c|}{$(\mathrm{mg} / \mathrm{L})$} \\
\hline \multicolumn{17}{|c|}{ Primeira Coleta 13/08/06 } \\
\hline $\mathrm{P} 1$ & 0,32 & 40,00 & 20,20 & 6,70 & 6,60 & 50,00 & 15,00 & 7,55 & 1,34 & 3,54 & 3,63 & 20,00 & 1,56 & 1,84 & 36,00 & 3,96 \\
\hline $\mathrm{P} 2$ & 0,51 & 30,00 & 17,70 & 6,70 & 6,30 & 30,00 & 20,00 & 3,96 & 0,92 & 2,38 & 1,42 & 15,00 & 1,28 & 1,98 & 30,00 & 4,52 \\
\hline P3 & 0,77 & 40,00 & 17,60 & 7,00 & 6,40 & 30,00 & 20,00 & 4,17 & 1,46 & 2,79 & 2,52 & 14,00 & 2,03 & 2,01 & 25,00 & 4,40 \\
\hline P4 & 0,82 & 190,00 & 16,90 & 6,70 & 2,90 & 130,00 & 25,00 & 11,69 & 1,62 & 59,84 & 3,82 & 23,00 & 44,64 & 4,30 & 80,00 & 7,72 \\
\hline P5 & 1,73 & 30,00 & 17,70 & 6,70 & 6,40 & 60,00 & 30,00 & 4,90 & 0,95 & 2,76 & 1,89 & 17,00 & 3,66 & 3,10 & 63,00 & 6,96 \\
\hline P6 & 3,27 & 30,00 & 21,60 & 6,80 & 6,00 & 50,00 & 30,00 & 8,50 & 1,48 & 5,33 & 3,17 & 15,00 & 2,43 & 2,28 & 55,00 & 4,84 \\
\hline P7 & 5,95 & 100,00 & 21,60 & 6,80 & 5,00 & 90,00 & 15,00 & 7,03 & 1,42 & 15,06 & 2,98 & 19,00 & 17,05 & 3,02 & 64,00 & 6,28 \\
\hline P8 & 9,61 & 30,00 & 19,80 & 7,20 & 7,00 & 15,00 & 5,00 & 5,49 & 1,36 & 5,37 & 2,06 & 8,00 & 0,75 & 0,08 & 12,00 & 0,44 \\
\hline \multicolumn{17}{|c|}{ Segunda Coleta 20/09/06 } \\
\hline $\mathrm{P} 1$ & 0,59 & 50,00 & 22,00 & 7,00 & 6,70 & 60,00 & 36,00 & 7,89 & 2,40 & 7,56 & 6,51 & 22,00 & 1,35 & 1,48 & 34,00 & 3,52 \\
\hline $\mathrm{P} 2$ & 0,96 & 30,00 & 19,10 & 7,10 & 6,80 & 40,00 & 28,00 & 4,83 & 1,31 & 4,71 & 2,42 & 16,00 & 0,91 & 1,39 & 28,00 & 4,26 \\
\hline P3 & 1,45 & 40,00 & 18,70 & 7,30 & 6,90 & 40,00 & 28,00 & 4,70 & 1,92 & 5,66 & 2,71 & 18,00 & 1,86 & 1,51 & 19,00 & 3,64 \\
\hline P4 & 1,53 & 210,00 & 18,90 & 7,10 & 2,90 & 150,00 & 36,00 & 11,90 & 2,90 & 61,90 & 7,30 & 25,00 & 40,31 & 3,81 & 77,00 & 7,42 \\
\hline P5 & 3,24 & 30,00 & 18,80 & 7,10 & 6,50 & 80,00 & 44,00 & 4,99 & 1,32 & 7,24 & 2,91 & 18,00 & 3,22 & 2,48 & 59,00 & 6,60 \\
\hline P6 & 6,14 & 40,00 & 21,10 & 7,20 & 6,60 & 60,00 & 40,00 & 9,22 & 1,90 & 6,54 & 4,00 & 18,00 & 2,18 & 1,86 & 51,00 & 3,96 \\
\hline P7 & 11,16 & 130,00 & 19,00 & 7,00 & 5,00 & 110,00 & 41,00 & 7,44 & 2,31 & 16,80 & 3,22 & 20,00 & 15,03 & 2,56 & 59,00 & 6,04 \\
\hline P8 & 9,01 & 30,00 & 21,20 & 7,50 & 7,00 & 20,00 & 10,00 & 6,19 & 1,50 & 6,19 & 2,11 & 8,00 & 0,72 & 0,08 & 11,00 & 0,44 \\
\hline \multicolumn{17}{|c|}{ Terceira Coleta 18/10/06 } \\
\hline $\mathrm{P} 1$ & 0,64 & 50,00 & 22,30 & 7,00 & 7,00 & 80,00 & 38,00 & 8,68 & 2,71 & 7,68 & 6,70 & 30,00 & 1,23 & 0,92 & 27,00 & 2,96 \\
\hline $\mathrm{P} 2$ & 1,04 & 30,00 & 20,20 & 7,10 & 6,90 & 60,00 & 40,00 & 5,26 & 1,43 & 4,96 & 2,71 & 17,00 & 0,80 & 0,84 & 24,00 & 4,02 \\
\hline P3 & 1,57 & 40,00 & 20,50 & 7,30 & 7,00 & 60,00 & 38,00 & 6,86 & 2,00 & 6,25 & 2,80 & 24,00 & 1,56 & 0,59 & 15,00 & 3,26 \\
\hline $\mathrm{P} 4$ & 1,66 & 250,00 & 20,10 & 7,20 & 3,10 & 180,00 & 50,00 & 12,80 & 3,00 & 68,50 & 7,63 & 42,00 & 38,21 & 2,86 & 64,00 & 6,98 \\
\hline P5 & 3,51 & 30,00 & 20,80 & 7,20 & 6,90 & 100,00 & 51,00 & 5,81 & 1,52 & 7,78 & 2,90 & 27,00 & 2,65 & 1,97 & 39,00 & 4,44 \\
\hline P6 & 6,66 & 40,00 & 22,10 & 7,30 & 6,90 & 80,00 & 48,00 & 10,70 & 2,11 & 6,72 & 4,11 & 32,00 & 1,97 & 1,43 & 26,00 & 3,52 \\
\hline P7 & 12,11 & 140,00 & 20,50 & 7,10 & 5,30 & 140,00 & 50,00 & 8,83 & 2,42 & 18,60 & 3,31 & 30,00 & 13,56 & 2,17 & 46,00 & 5,28 \\
\hline P8 & 9,96 & 30,00 & 23,20 & 7,80 & 7,30 & 20,00 & 11,00 & 6,61 & 1,60 & 6,93 & 2,60 & 10,00 & 0,70 & 0,08 & 10,00 & 0,44 \\
\hline
\end{tabular}


Tabela 2 - Parâmetros físico-químicos e químicos na bacia do Alto Sorocaba durante o período chuvoso. P1 e P4 = Rio de Una, P2 e P5 = Rio Sorocabuçu, P3 e P6 = Rio Sorocamirim e P7 e P8 = Rio Sorocaba.

\begin{tabular}{|c|c|c|c|c|c|c|c|c|c|c|c|c|c|c|c|c|}
\hline \multirow{2}{*}{$\begin{array}{l}\text { Ponto de } \\
\text { coleta }\end{array}$} & \multirow{2}{*}{$\begin{array}{l}\text { Vazão } \\
\left(\mathrm{m}^{3} / \mathrm{s}\right)\end{array}$} & \multirow{2}{*}{$\begin{array}{l}\text { Cond, } \\
(\mu \mathrm{S} / \mathrm{cm})\end{array}$} & \multirow{2}{*}{$\begin{array}{l}\text { Temp } \\
\left({ }^{\circ} \mathrm{C}\right)\end{array}$} & \multirow{2}{*}{$\mathrm{pH}$} & OD & STD & STS & $\mathrm{Ca}^{2+}$ & $\mathrm{Mg}^{2+}$ & $\mathrm{Na}^{+}$ & $\mathrm{K}^{+}$ & $\mathrm{HCO}_{3}^{-}$ & $\mathrm{Cl}^{-}$ & $\mathrm{PO}_{4}^{3-}$ & $\mathrm{SO}_{4}^{2-}$ & $\mathrm{NO}_{3}$ \\
\hline & & & & & \multicolumn{12}{|c|}{$(\mathrm{mg} / \mathrm{L})$} \\
\hline \multicolumn{17}{|c|}{ Quarta Coleta 23/11/06 } \\
\hline $\mathrm{P} 1$ & 0,30 & 50,00 & 23,10 & 7,10 & 7,20 & 100,00 & 40,00 & 9,68 & 2,80 & 7,97 & 6,93 & 37,00 & 1,02 & 0,86 & 20,00 & 2,58 \\
\hline $\mathrm{P} 2$ & 0,48 & 30,00 & 20,40 & 7,40 & 7,40 & 100,00 & 43,00 & 5,83 & 1,62 & 5,09 & 3,21 & 21,00 & 0,59 & 0,83 & 18,00 & 3,82 \\
\hline $\mathrm{P} 3$ & 0,73 & 40,00 & 20,80 & 7,40 & 7,50 & 70,00 & 41,00 & 6,97 & 2,47 & 6,70 & 3,30 & 31,00 & 1,35 & 0,57 & 12,00 & 2,84 \\
\hline P4 & 0,77 & 270,00 & 21,00 & 7,30 & 3,50 & 260,00 & 62,00 & 13,41 & 3,84 & 69,11 & 8,20 & 44,00 & 36,31 & 2,75 & 56,00 & 5,72 \\
\hline P5 & 1,63 & 30,00 & 21,90 & 7,30 & 7,30 & 120,00 & 60,00 & 5,95 & 1,63 & 7,87 & 3,01 & 32,00 & 2,04 & 1,94 & 21,00 & 3,96 \\
\hline P6 & 3,08 & 40,00 & 23,60 & 7,20 & 7,20 & 100,00 & 55,00 & 10,42 & 2,70 & 6,97 & 4,71 & 42,00 & 1,45 & 1,40 & 15,00 & 2,82 \\
\hline $\mathrm{P} 7$ & 5,60 & 150,00 & 22,30 & 7,30 & 5,40 & 170,00 & 60,00 & 9,04 & 2,80 & 19,85 & 3,60 & 32,00 & 10,17 & 2,07 & 26,00 & 4,84 \\
\hline P8 & 8,79 & 30,00 & 26,80 & 8,10 & 7,50 & 50,00 & 13,00 & 6,83 & 1,91 & 7,42 & 2,70 & 12,00 & 0,59 & 0,08 & 9,00 & 0,44 \\
\hline \multicolumn{17}{|c|}{ Quinta Coleta 19/12/06 } \\
\hline P1 & 0,50 & 50,00 & 27,90 & 7,30 & 7,20 & 120,00 & 41,00 & 9,85 & 3,08 & 8,33 & 8,93 & 44,00 & 0,39 & 0,68 & 12,00 & 2,20 \\
\hline P2 & 0,81 & 30,00 & 23,60 & 7,50 & 7,40 & 140,00 & 46,00 & 6,22 & 1,85 & 5,28 & 3,42 & 28,00 & 0,32 & 0,77 & 8,00 & 2,64 \\
\hline P3 & 1,22 & 50,00 & 24,10 & 7,50 & 7,50 & 80,00 & 44,00 & 7,25 & 2,61 & 6,91 & 3,50 & 42,00 & 0,72 & 0,55 & 11,00 & 2,76 \\
\hline P4 & 1,28 & 290,00 & 24,20 & 7,50 & 3,60 & 300,00 & 70,00 & 15,44 & 4,08 & 70,71 & 9,03 & 46,00 & 32,86 & 2,45 & 47,00 & 5,36 \\
\hline P5 & 2,71 & 40,00 & 25,60 & 7,40 & 7,40 & 140,00 & 66,00 & 6,53 & 2,11 & 8,05 & 3,85 & 35,00 & 1,02 & 1,92 & 14,00 & 3,52 \\
\hline P6 & 5,15 & 40,00 & 31,30 & 7,40 & 7,40 & 120,00 & 60,00 & 10,81 & 2,90 & 7,55 & 4,91 & 44,00 & 0,77 & 1,35 & 12,00 & 2,64 \\
\hline P7 & 9,37 & 160,00 & 26,90 & 7,50 & 5,50 & 190,00 & 65,00 & 10,10 & 3,10 & 20,31 & 4,01 & 40,00 & 9,33 & 1,93 & 21,00 & 4,16 \\
\hline $\mathrm{P} 8$ & 7,22 & 40,00 & 28,20 & 8,20 & 7,90 & 60,00 & 15,00 & 7,05 & 1,94 & 7,56 & 2,93 & 12,00 & 0,47 & 0,06 & 9,00 & 0,44 \\
\hline \multicolumn{17}{|c|}{ Sexta Coleta 10/01/07 } \\
\hline $\mathrm{P} 1$ & 1,67 & 60,00 & 23,70 & 7,30 & 7,30 & 240,00 & 70,00 & 10,11 & 3,35 & 9,07 & 9,04 & 30,00 & 0,22 & 0,23 & 6,00 & 2,20 \\
\hline P2 & 2,71 & 40,00 & 22,60 & 7,40 & 7,40 & 200,00 & 50,00 & 7,03 & 2,00 & 5,93 & 3,66 & 17,00 & 0,32 & 0,26 & 7,00 & 2,64 \\
\hline P3 & 4,09 & 50,00 & 22,80 & 7,50 & 7,50 & 100,00 & 49,00 & 8,82 & 2,71 & 7,46 & 4,11 & 24,00 & 0,34 & 0,22 & 10,00 & 2,08 \\
\hline P4 & 4,32 & 400,00 & 22,70 & 7,60 & 3,90 & 360,00 & 75,00 & 16,70 & 4,22 & 72,00 & 9,74 & 42,00 & 28,21 & 1,23 & 13,00 & 5,02 \\
\hline P5 & 9,14 & 40,00 & 22,90 & 7,50 & 7,40 & 160,00 & 70,00 & 7,38 & 2,45 & 8,83 & 3,91 & 27,00 & 0,42 & 0,37 & 8,00 & 3,08 \\
\hline P6 & 17,33 & 50,00 & 25,60 & 7,60 & 7,50 & 140,00 & 63,00 & 11,32 & 3,41 & 7,54 & 5,10 & 32,00 & 0,45 & 0,25 & 11,00 & 2,44 \\
\hline P7 & 31,50 & 190,00 & 23,70 & 7,60 & 5,80 & 210,00 & 68,00 & 10,84 & 3,80 & 24,51 & 4,14 & 30,00 & 8,91 & 0,82 & 12,00 & 3,84 \\
\hline P8 & 11,00 & 50,00 & 25,40 & 8,30 & 8,10 & 80,00 & 20,00 & 7,56 & 2,00 & 9,22 & 3,10 & 10,00 & 0,33 & 0,07 & 8,00 & 0,44 \\
\hline
\end{tabular}

agosto de 2006 e janeiro de 2007.

$\mathrm{O}$ pH é governado pelo equilíbrio do dióxido de carbono-bicarbonato e carbonatos, podendo alterar o processo de permeabilidade da membrana celular. Os valores obtidos em todos os pontos de amostragem indicam que as águas da bacia são praticamente neutras, encontrando-se dentro da faixa de proteção da vida aquática, preconizadas pela Legislação Federal (Resolução CONAMA n ${ }^{\circ} 357 / 05$ ) e Estadual (Decreto $n^{\circ} 8.468 / 76$ ) para a Classe 2, como são enquadrados os rios da bacia do Alto Sorocaba. Um valor de $\mathrm{pH}$ médio ligeiramente superior ocorreu na época de chuva $(7,5)$ em relação à seca $(7,1)$. Em todas as coletas, valores mais elevados de $\mathrm{pH}$ sempre foram caracterizados no Rio Sorocaba após o Reservatório de Itupararanga (P8), o que possivelmente se deve à intensa fotossíntese realizada pelas algas no Reservatório de Itupararanga (Esteves, 1988).

A atmosfera e a fotossíntese são as principais fontes de oxigênio para as águas fluviais. Por outro lado, as perdas de oxigênio se devem ao consumo pela decomposição da matéria orgânica, trocas para a atmos- fera, respiração de organismos aquáticos e oxidação de íons metálicos (Esteves, 1988). Há um ligeiro aumento nos valores médios de oxigênio dissolvido da época seca $(6,0 \mathrm{mg} / \mathrm{L})$ para a de chuva $(6,7 \mathrm{mg} / \mathrm{L})$, sendo os valores mais elevados geralmente quantificados no ponto $\mathrm{P} 8$, fato que também pode ser atribuído à elevada fotossíntese das algas no Reservatório de Itupararanga. As menores concentrações de oxigênio dissolvido foram sempre encontradas no Rio de Una (P4), fato que pode ser atribuído à decomposição de matéria orgânica oriunda dos efluentes domésticos da cidade de Ibiúna. Apesar dos baixos valores encontrados neste ponto, a concentração de oxigênio dissolvido no ponto P7 (Rio Sorocaba) já apresenta valores maiores ou iguais a 5 $\mathrm{mg} / \mathrm{L}$ (mínimo permitido para a Classe 2), devido à contribuição de águas com maiores teores de oxigênio dissolvido dos Rios Sorocabuçu e Sorocamirim.

Todas as impurezas encontradas no curso da água, exceto os gases dissolvidos, contribuem para a carga de sólidos totais presentes nos corpos d'água (Espíndola et al., 2000). Na maioria das coletas, os valo- 
res de sólidos totais dissolvidos (STD) e sólidos totais em suspensão (STS) aumentam ao longo de todos os afluentes do Rio Sorocaba. Os maiores e menores valores de STD sempre foram encontrados nos pontos P4 e P8, respectivamente. Para STS, os menores valores sempre foram encontrados em P8. Os valores médios de STD e STS aumentam na época de verão, mesmo comportamento da vazão, indicando uma maior descarga durante esta época, em acordo com a maioria dos rios mundiais (Berner \& Berner, 1996; Conceição \& Bonotto, 2004; Conceição et al., 2007). O aumento dos valores de STS na época chuvosa pode ser atribuído ao maior arraste de sedimentos pela erosão laminar que é muito acentuada neste período.

Composição iônica As tabelas 1 e 2 apresentam os valores para a composição iônica das águas fluviais da bacia do Alto Sorocaba. A figura 3 ilustra as concentrações médias ponderadas dos cátions e ânions, sendo determinadas a partir da equação 2 :

$$
C_{E}=\frac{\sum_{i=1}^{n} C_{i} \cdot V_{i}}{\sum_{i=1}^{n} V_{i}}
$$

Onde:

$C_{E}=$ média ponderada do parâmetro $(\mathrm{mg} / \mathrm{L})$; $C_{i}=$ concentração do parâmetro na i-ésima amostra $(\mathrm{mg} / \mathrm{L}) ; Q_{i}=$ vazão do rio durante a coleta da i-ésima $\operatorname{amostra}\left(\mathrm{m}^{3} / \mathrm{s}\right)$.

O cálcio influencia a ciclagem do fosfato, além de interferir no $\mathrm{pH}$ das águas fluviais e pluviais (Wetzel, 1983). O magnésio é um constituinte necessário da clorofila (Odum, 1988). Já o sódio possui as mesmas funções que o potássio, atuando na troca e transporte de outros íons para os meios intra e extracelulares (Esteves, 1998). Quanto aos cátions, com exceção do potássio, no rio de Una (P4) foram encontradas as maiores concentrações em relação aos demais pontos. Há um aumento dos valores médios para estes parâmetros da época seca para o período chuvoso, mesmo comportamento observado para o $\mathrm{pH}$, condutividade e STD. A alcalinidade decorre da presença de carbonatos, bicarbonatos e hidróxidos (Wetzel, 1983). Análise estatística de correlação foi realizada a partir dos resultados obtidos para as águas superficiais do Rio Sorocaba em P7, que é um local onde há um controle de vazão nas comportas da represa de Itupararanga pela CBA (Companhia Brasileira de Alumínio). $\mathrm{O}$ aumento na concentração de bicarbonato o dos metais alcalinos $\mathrm{Na}, \mathrm{K}, \mathrm{Ca}$ e $\mathrm{Mg}$ contribui para a elevação do pH das águas, também justificando a correlação direta entre STD e pH (Fig. 4).

Quanto ao cloreto, sua presença nas águas naturais se deve à alteração das rochas, dentre outros fatores (CETESB, 2005). O fósforo é um elemento fundamental para o metabolismo dos seres vivos (Esteves, 1988). O íon sulfato constitui a principal fonte de enxofre para os produtores primários (Tundisi, 2006). O nitrato é en-
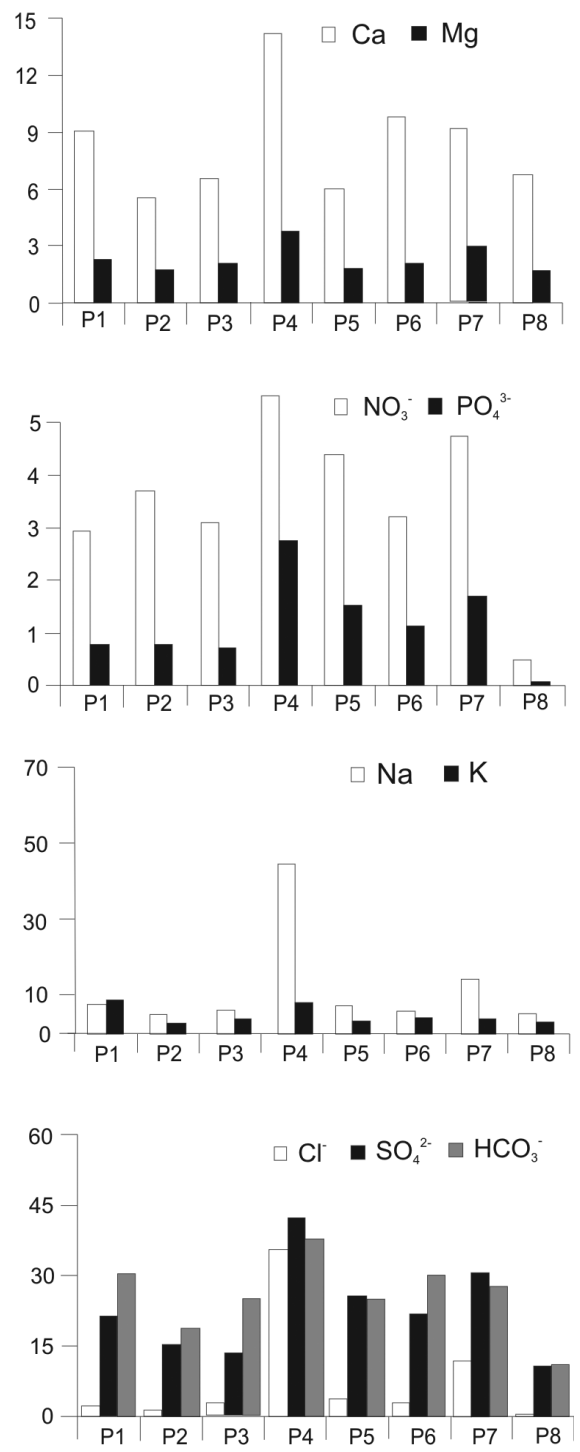

Figura 3 - Concentração média ponderada de cátions e ânions (mg/L) para as águas fluviais da bacia do Alto Sorocaba. Pl e P4 = Rio de Una, P2 e P5 = Rio Sorocabuçu, P3 e P6 = Rio Sorocamirim e P7 e P8 = Rio Sorocaba.

contrado em águas como resultado da oxidação de compostos nitrogenados (Tundisi, 2005). Cloreto, sulfato e nitrato apresentam valores de concentração menores que os permitidos para a Classe 2, segundo a Resolução do CONAMA 357/05, isto é, $250 \mathrm{mg} / \mathrm{L}, 250 \mathrm{mg} / \mathrm{L}$ e $10 \mathrm{mg} / \mathrm{L}$, respectivamente. Todos os valores de fosfato apresentados nas tabelas 1 e 2 estão acima do permitido para a Classe 2 desta resolução, isto é, $0,050 \mathrm{mg} / \mathrm{L}$. Os pontos P4 e P8 são os locais com maior e menor contribuição desses ânions para as águas fluviais da bacia do Alto Sorocaba, respectivamente (Fig. 3). Além disso, com exceção de bicarbonato, há uma diminuição dos valores médios de concentração dos ânions da época seca para o período chuvoso, opostamente ao observado para o $\mathrm{pH}$, condutividade, STD e cátions. 

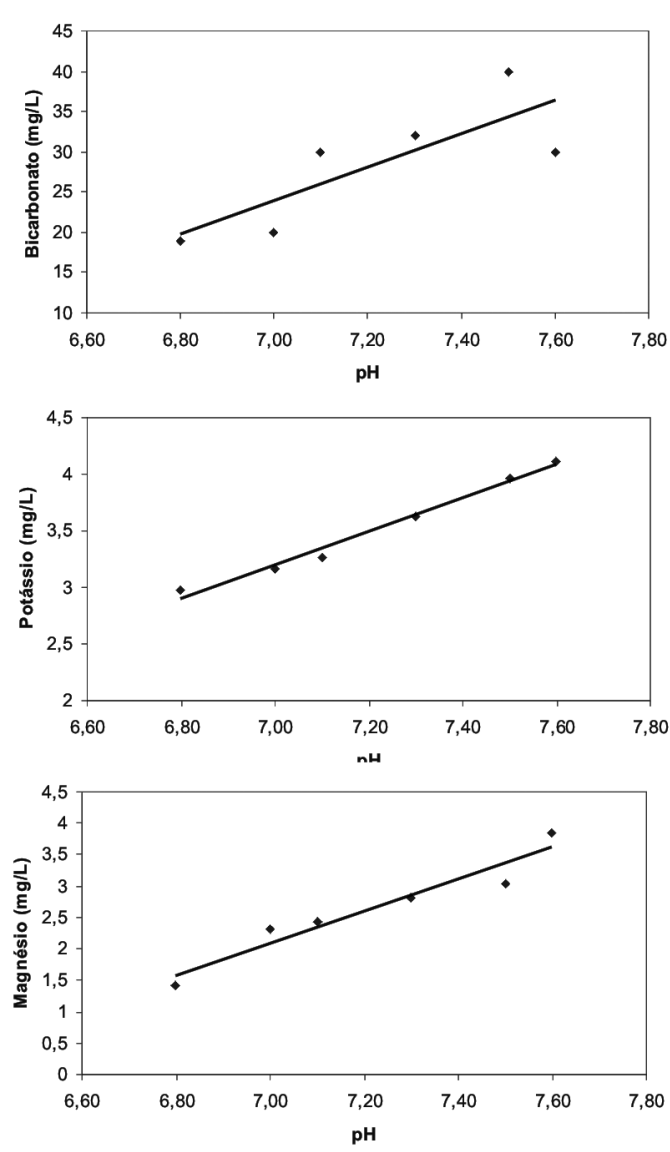
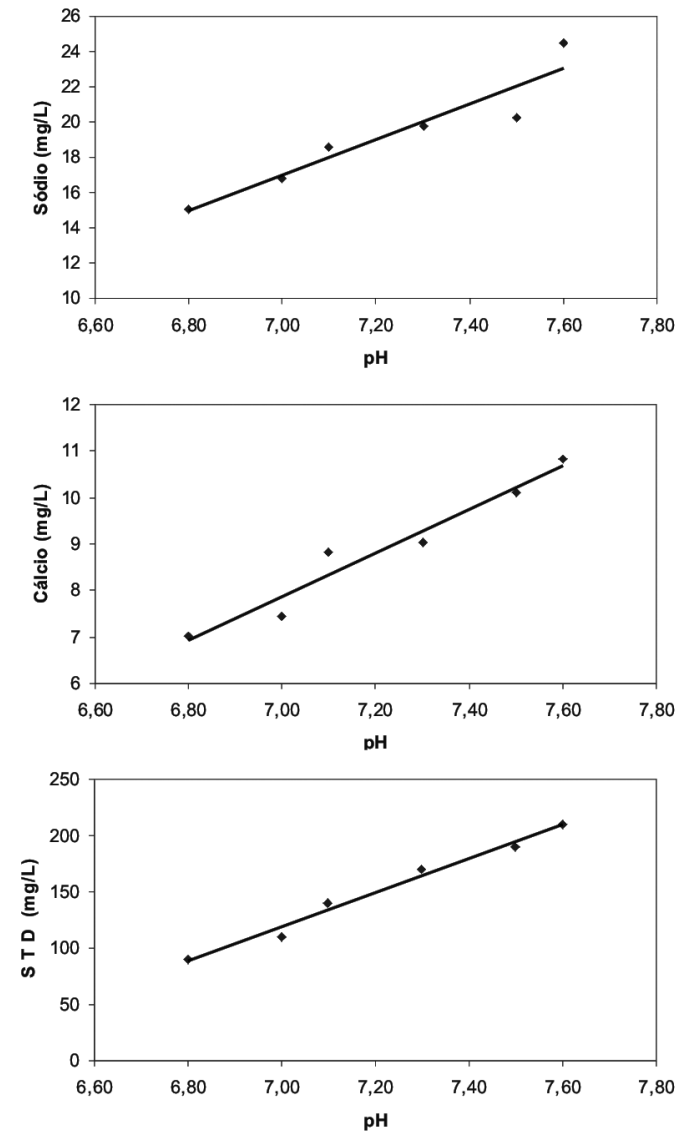

Figura 4 - Correlações entre os parâmetros obtidos nas águas superficiais do Rio Sorocaba (P7): (a) bicarbonato e pH; (b) sódio e pH; (c) potássio e pH; (d) cálcio e pH; (e) magnésio e pH; (f) sólidos totais dissolvidos e $\mathrm{pH}$.

Utilizando-se os valores médios obtidos para os principais cátions e ânions discutidos neste estudo, é possível classificar quimicamente as águas dos rios da bacia do Alto Sorocaba a partir do diagrama de Piper (1944). De acordo com a figura 5, as águas fluviais podem ser classificadas como sódico-potássicas e sulfatadas, em relação aos cátions e ânions, respectivamente.

DISCUSSÕES Garrels \& Mackenzie (1967) modelaram a abundância e proporção relativa de íons dissolvidos em águas fluviais, usando uma equação de balanço de massa. Contudo, a entrada de elementos e/ ou componentes leva a uma importante correção para se obter a fração proveniente da dissolução das rochas. Assim, White \& Blum (1995) sumarizaram a dinâmica química ocorrendo num rio por meio da equação 3 :

$F_{W}=F_{\text {river }}-F_{\text {wetall }}-F_{\text {dryfall }} \pm F_{\text {ion exchange }} \pm F_{\text {bio }}-F_{\text {anthropogenic }}$

Onde:

$F_{W}=$ fluxo anual do elemento nas águas do rio (ton/ano); $F_{\text {river }}=$ fluxo quantificado do elemento nas águas do rio (ton/ano); $F_{\text {wetfall }}$ e $F_{\text {dryall }}=$ entradas atmosféricas (ton/ano); $F_{\text {ion exchange }}=$ elementos dissolvidos a partir de trocas iônicas em argilo minerais (ton/ano); $F_{b i o}=$ ele- mentos dissolvidos devido a mudanças na biomassa (ton/ ano); $F_{\text {anthropogenic }}=$ entradas antropogênicas (ton/ano).

O exutório da bacia do Alto Sorocaba deveria ser utilizado para a avaliação de balanço anual de cátions e ânions. Porém, como demonstrado pelos resultados apresentados, há uma redução muito grande na concentração de cátions e ânions neste ponto de amostragem (P8), devido à influência do Reservatório de Ituparanranga (Tabs. 1 e 2), tornando-o impróprio para a modelagem proposta. O Rio Sorocaba, antes de entrar no Reservatório de Itupararanga, também sofre severos impactos ambientais que alteram sua qualidade. $\mathrm{O}$ crescimento urbano de Ibiúna, sem planejamento, com o descarte de efluentes domésticos e industriais "in natura" no Rio de Una faz com que óleos, lixo, cor, odor, larvas e vermes vermelhos (Chironomidae) sejam componentes da paisagem, conforme observado em P4. A degradação da qualidade da água, ao passar pelo município de Ibiúna (P4) é evidenciada pelos valores mais acentuados obtidos para cátions e ânions. Os pontos P5 e P6 drenam uma área onde o uso de fertilizantes e queimadas por parte das propriedades agrícolas podem ocasionar a liberação de grandes quantidades de macronutrientes (nitrogênio, fósforo e potássio). O Rio Sorocabuçu (P5) e o Rio Sorocamirim (P6) não passam por nenhum centro urbano, 


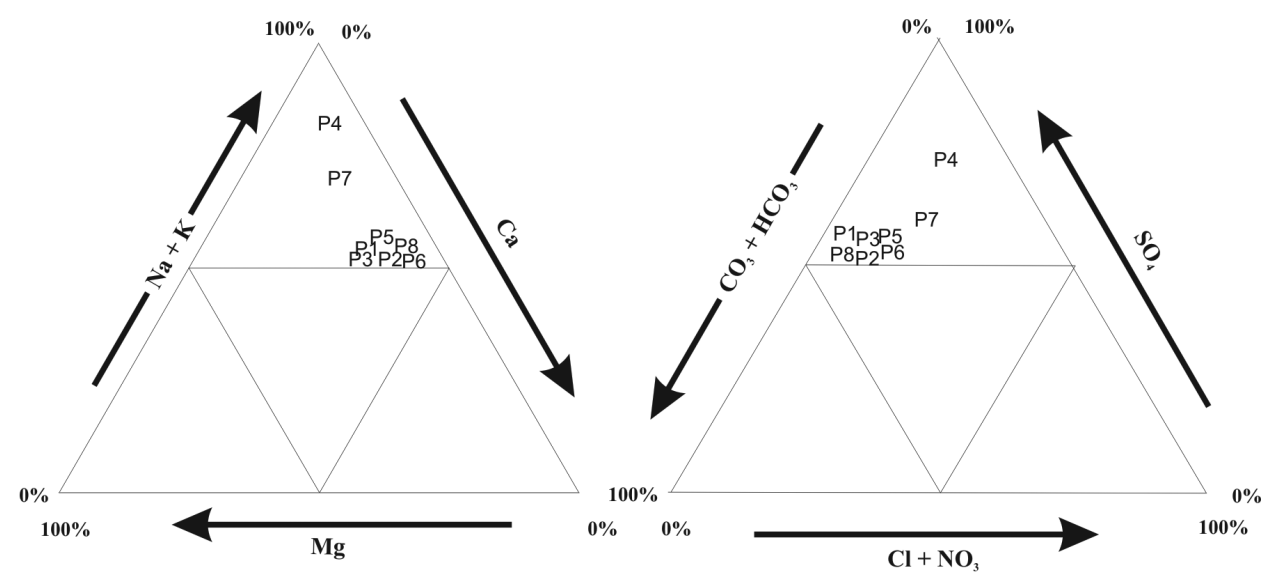

Figura 5 - Classificação das águas superficiais da bacia do Alto Sorocaba de acordo com o diagrama de Piper (1944). P1 e P4 = Rio de Una, P2 e P5 = Rio Sorocabuçu, P3 e P6 = Rio Sorocamirim e P7 e P8 = Rio Sorocaba.

porém, podem receber possíveis cargas difusas, devido ao cultivo de olerícolas (repolho, alface, batata, tomate, etc.) ou pela presença de pequenos aglomerados populacionais ao longo de sua extensão.

Assim, entradas antropogênicas estão afetando os cálculos da avaliação do fluxo anual de cátions e ânions, sendo necessário corrigir os valores destas entradas. Os pontos $\mathrm{P} 1, \mathrm{P} 2$ e $\mathrm{P} 3$ poderiam representar as condições naturais intempéricas atuando na bacia do Alto Sorocaba, mesmo tendendo a sofrer impactos devido às ações antropogênicas e, por isso, poderiam ser usados em estimativas de remoção de cátions e ânions. Com isso, um balanço de massa entre os tributários do Rio Sorocaba nos pontos de amostragem dos rios de Una (P1), Sorocabuçu (P2) e Sorocamirim (P3) e o Rio Sorocaba antes do Reservatório de Itupararanga (P7) pode ser usado para este propósito, ou seja (eq. 4):

$$
Q_{R S} C_{R S}=Q_{R U} C_{R U}+Q_{R S M} C_{R S M}+Q_{R S U} C_{R S U}
$$

Onde:

$Q_{R S}=$ soma da vazão dos tributários $\left(\mathrm{m}^{3} / \mathrm{s}\right) ; C_{R S}$ = concentração corrigida no Rio Sorocaba $(\mathrm{mg} / \mathrm{L}) ; Q_{R U}$ = vazão do Rio de Una $\left(\mathrm{m}^{3} / \mathrm{s}\right) ; C_{R U}=$ concentração média do elemento no Rio de Una (mg/L); $Q_{R S M}=$ vazão no Rio Sorocamirim $\left(\mathrm{m}^{3} / \mathrm{s}\right) ; C_{R S M}=$ concentração média do elemento no Rio Sorocamirim (mg/L); $Q_{R S U}=$ vazão no Rio Sorocabuçu $\left(\mathrm{m}^{3} / \mathrm{s}\right) ; C_{R S U}=$ concentração média do elemento no Rio Sorocabuçu (mg/L).

Os valores corrigidos para a concentração de cátions e ânions gerados pelo uso da equação 4 são mostrados na tabela 3. Os elementos dissolvidos a partir de trocas iônicas em argilo minerais $\left(F_{\text {ion exchange }}\right)$ é considerado significantemente menor que o removido de cátions e ânions devido às reações de intemperismo químico. Grasby \& Hutcheon (2000) sugerem que a entrada ou saída de elementos dissolvidos devido a mudanças na biomassa $\left(F_{\text {bio }}\right)$ em uma bacia hidrográfica deve ser constante se não houver mudança na biomassa da região, o que é assumido para a área em estudo. Os impactos antropogênicos não são muito pronunciados nos pontos de amostragem P1, P2 e P3, em relação a P4, P5 e P6, gerando dados mais representativos de águas não poluídas. Assim, com estas considerações, a equação 3 pode reduzida para a equação 5:

$$
F_{W}=F_{\text {river }}-F_{\text {wetfall }}-F_{\text {dryfall }}
$$

Assim, a equação 5 implica no fato de que a química no Rio Sorocaba somente precisaria ser corrigida pelos aportes atmosféricos. O fluxo anual $(F w)$ de cátions e ânions nas águas fluviais na bacia do Alto Sorocaba pode ser calculado utilizando a equação 5 (Tab. 4). Para tanto, foram empregados os dados corrigidos para a concentração média ponderada dos elementos nas águas fluviais do Rio Sorocaba (Tab. 3) e a vazão média afluente do Rio Sorocaba no Reservatório de Itupararanga (12,70 $\mathrm{m}^{3} / \mathrm{s}$, conforme Tabs. 1 e 2), e as deposições atmosféricas anuais de cátions e ânions apresentadas por Angelucci et al. (submetido) para a bacia do Alto Sorocaba.

Tabela 3 - Concentrações medidas (valor médio) e corrigidas ( $\mathrm{mg} / \mathrm{L})$ no Rio Sorocaba (P7) para os principais cátions e ânions dissolvidos.

\begin{tabular}{c|ccccccccc}
\hline Valor & $\mathrm{Ca}^{2+}$ & $\mathrm{Mg}^{2+}$ & $\mathrm{Na}^{+}$ & $\mathrm{K}^{+}$ & $\mathrm{HCO}_{3}^{-}$ & $\mathrm{SO}_{4}^{2-}$ & $\mathrm{NO}_{3}^{-}$ & $\mathrm{Cl}^{-}$ & $\mathrm{PO}_{4}^{3-}$ \\
\hline Medido & 8,88 & 2,64 & 19,16 & 3,52 & 28,50 & 38,00 & 5,07 & 12,34 & 2,10 \\
Corrigido & 6,65 & 2,03 & 5,84 & 3,75 & 24,41 & 17,97 & 3,27 & 1,05 & 0,96 \\
\hline
\end{tabular}


Tabela 4 - Balanço anual de cátions e ânions (ton/ano) na bacia do Alto Sorocaba.

\begin{tabular}{c|ccccccccc}
\hline Espécie & $\mathrm{Ca}^{2+}$ & $\mathrm{Mg}^{2+}$ & $\mathrm{Na}^{+}$ & $\mathrm{K}^{+}$ & $\mathrm{HCO}_{3}^{-}$ & $\mathrm{SO}_{4}^{2-}$ & $\mathrm{NO}_{3}^{-}$ & $\mathrm{Cl}^{-}$ & $\mathrm{PO}_{4}^{{ }^{3-}}$ \\
\hline Friver & 2648,1 & 804,4 & 2326,2 & 1494,0 & 9708,3 & 7148,9 & 1299,8 & 415,4 & 381,9 \\
$\mathrm{~F}_{\text {wetfall }}-\mathrm{F}_{\text {dryall }}{ }^{-}$ & 3486,1 & 167,6 & 1434,6 & 422,3 & 3685,0 & 4133,9 & 1474,0 & 656,6 & 160,8 \\
\hline $\mathrm{FW}$ & $-838,0$ & 636,8 & 892,3 & 1072,7 & 6023,3 & 3015,0 & $-174,2$ & $-241,2$ & 221,1 \\
\hline
\end{tabular}

${ }^{1}$ Angelucci et al. (submetido).

Os resultados obtidos na tabela 4 indicam que o cálcio, nitrato e cloreto possuem fluxos anuais maiores nas águas de chuva medidos antes de atingir a superfície. A primeira explicação para a alta deposição de $\mathrm{Ca}$ nesta bacia reside na dissolução de $\mathrm{Ca}$ $\mathrm{CO}_{3}$ proveniente de poeiras de solos, como descrito em outras áreas (Moreira-Nordemann et al., 1997; Lara et al., 2001; Conceição \& Bonotto, 2004). A segunda explicação seria a entrada de Ca pelas atividades antrópicas. $\mathrm{Na}$ bacia existem as maiores minerações de calcário dolomítico $\left(\mathrm{CaMg}\left(\mathrm{CO}_{3}\right)_{2}\right)$ e fábricas de cimento do Brasil, e, conseqüentemente, muito material particulado deve ser liberado para a atmosfera durante as atividades exploratórias e de processamento. A presença de nitrato na atmosfera pode ser atribuída ao tráfego de veículos e à queima de combustível fóssil por atividades industriais, as quais são as principais e permanentes fontes de sua presença na água de chuva (Conceição \& Bonotto, 2004). Uma fonte adicional de $\mathrm{NO}_{3}^{-}$seriam as emissões geradas a partir de diversas carvoarias existentes na região. Já os valores encontrados para a deposição anual de $\mathrm{Cl}^{-}$na bacia poderiam ser explicados pelos aportes marinhos e por várias fontes antrópicas de poluição, como queima de combustível fóssil por veículos, queima de carvão, incineradores, fertilizantes, combustão ou decomposição de compostos organoclorados e indústrias de papel (Sanusi et al., 1996;
Négrel \& Roy, 1998; Conceição \& Bonotto, 2004).

Os pontos P1, P2 e P3 estão situados em regiões com menor presença de poluição, como indicado pelos parâmetros físico-químicos e químicos apresentados nas tabelas 1 e 2 . Assim, estes pontos possuem características mais próximas ao comportamento natural de cátions e ânions dissolvidos nas águas da bacia do Alto Sorocaba. Pedro \& Sieffermann (1979) consideraram que parte da origem de cátions e ânions nas águas superficiais é devido ao intemperismo das rochas, segundo a reação: Minerais primários $+\mathrm{H}_{2} \mathrm{O}+\mathrm{CO}_{2}{ }^{\circledR}$ minerais secundários (argilas) $+\mathrm{HCO}_{3}^{-}+\mathrm{H}_{2} \mathrm{SiO}_{4}+$ solução lixiviada. A degradação primária ou total destruição das estruturas dos minerais primários pode produzir fases secundárias, onde o processo é fortemente influenciado pela natureza dos minerais primários, clima, biosfera e pelo tempo (Martini \& Chesworth, 1992).

Em relação aos processos intempéricos, a bacia do Alto Sorocaba está inserida em uma região onde o clima (pluviosidade de $1.492,7 \mathrm{~mm} /$ ano e temperatura de $20^{\circ} \mathrm{C}$ ) causa uma alteração química moderada, com predomínio do processo de monossialitização. Esse processo ocorre pela hidrólise parcial da rocha mãe, com parte do Si permanecendo no perfil de alteração e $\mathrm{Na}, \mathrm{Ca}, \mathrm{K}$ e Mg sendo eliminados (Toledo et al., 2000). Possíveis reações envolvendo os processos de intemperismo na bacia do Alto Sorocaba são apresentadas na figura 6. Em geral, $\mathrm{Na}$ e $\mathrm{Ca}$ podem ser liberados pela

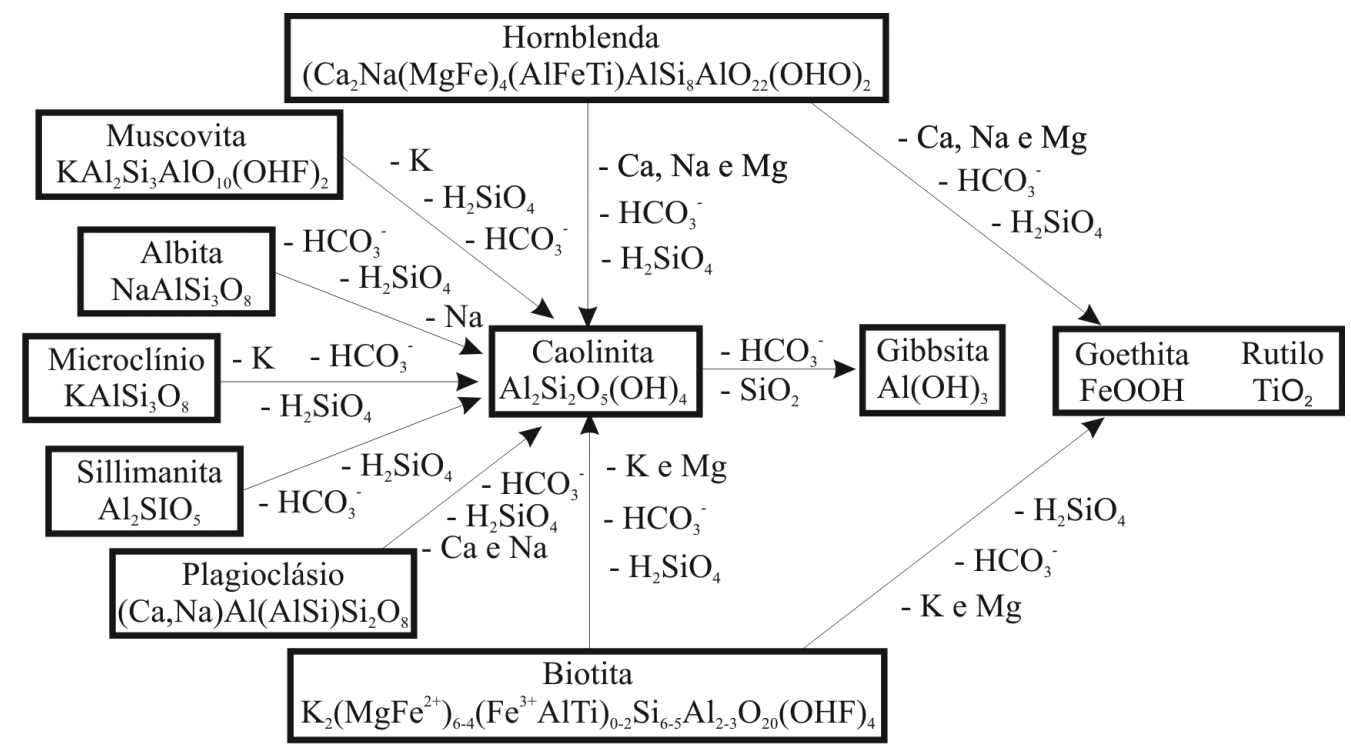

Figura 6 - Possíveis reações envolvendo os minerais constituintes dos granitos Ibiúna e Caucaia e dos gnaisses migmatíticos do Complexo Embu. 
hidrólise do plagioclásio e hornblenda, K pela hidrólise da biotita, muscovita e feldspato potássico e Mg pela hidrólise da biotita, muscovita e hornblenda. Quartzo $\left(\mathrm{SiO}_{2}\right)$ é um mineral comum na composição da maioria das rochas da bacia do Alto Sorocaba, porém, este mineral é resistente aos processos intempéricos na bacia do Alto Sorocaba (Toledo et al., 2000).

CONCLUSÃO Os resultados da presente investigação hidroquímica conduzida na bacia do Alto Sorocaba levaram em conta parâmetros que permitiram avaliar os valores de balanço anual de cátions e ânions nos rios desta bacia, além de caracterizar possíveis influências antropogênicas que interferem nestes valores. Em todos os pontos analisados, há uma diminuição dos valores médios de concentração de cloreto, fosfato, sulfato e nitrato da época seca para o período chuvoso, opostamente ao observado para o $\mathrm{pH}$, condutividade, STD e cátions, provavelmente devido ao maior efeito da erosão laminar que é mais acentuada nesta época do ano.

Os rios de Una (P1), Sorocabuçu (P2) e Sorocamirim (P3) possuem características mais próximas ao comportamento natural de cátions e ânions dissolvidos devido ao intemperismo dos granitos Ibiúna e Caucaia e dos gnaisses migmatíticos do Complexo Embu. No entanto, esses rios, após esses pontos, drenam áreas agrícolas e urbanas que afetam a sua qualidade e, conseqüentemente, os valores de transporte específico. Após a confluência dos rios de Una, Sorocabuçu e
Sorocamirim forma-se o rio Sorocaba (P7), cuja água apresenta características intermediárias àquelas de seus tributários. Certos constituintes, como fosfato e nitrato, contribuem para a proliferação de macrófitas e algas, justamente na entrada do Reservatório de Itupararanga. Porém, no exutório deste reservatório (P8), a água recupera sua qualidade, possivelmente pela sedimentação, absorção e/ou complexação dos elementos/compostos analisados neste estudo.

Com isto, verifica-se que a maioria dos problemas ambientais na bacia do Alto Sorocaba, provocados por atividades antrópicas, tem como causas principais a sua má utilização e falta de planejamento. Considerando a grande importância da bacia do Alto Sorocaba, tanto para o abastecimento da população, quanto pela sua relevância ecológica por abrigar as nascentes deste mesmo rio, deve ser incentivada uma política que englobe como principal prioridade o desenvolvimento sustentável. De forma a manter a qualidade de água do Rio Sorocaba e seus afluentes, é de extrema importância para a integridade do sistema como um todo que ocorra a proteção dos mananciais de abastecimento de água de Ibiúna, Sorocaba, Mairinque, Votorantim e São Roque, além de outras cidades que eventualmente necessitem deste importante recurso natural.

Agradecimentos Os autores agradecem à FAPESP (Processos n ${ }^{\circ}$ 06/54884-3, 06/55477-2 e 06/61208-4) pelo apoio concedido durante a realização deste trabalho.

\section{Referências}

Angelucci V.A., Conceição F.T., Antunes M.L.P., Sardinha D.S. (submetido). Composição química das águas pluviais e deposição atmosférica anual na bacia do Alto Sorocaba (SP). Revista Brasileira de Geofísica.

Berner E.K. \& Berner R.A. 1996. Global environment. Water, air and geochemical cycles. Prentice Hall, 367p.

Branco S.M. 1991. A água e o homem. In: Porto R.L.L. (org.) Hidrologia Ambiental. São Paulo, USP/ABRH, Coleção ABRH de Recursos Hídricos, 3:3-26.

COMPANHIA BRASILEIRA DE ALUMÍNIO (CBA). 2006. Dados de vazão e precipitação. Estação meteorológica na Represa de Itupararanga, Votorantim (SP).

COMPANHIA DE TECNOLOGIA DE SANEAMENTO AMBIENTAL. (CETESB). 2006. Decreto $n^{\circ} 8.468$, de 8 de setembro de 1976. Aprova o regulamento da Lei $\mathrm{n}^{\circ}$ 997, de 31 de maio de 1976, que dispõe sobre a Prevenção e Controle da Poluição do Meio Ambiente. Disponível em http://www.cetesb.sp.gov.br/Institucional/ portugues_leis_dec.asp. Acesso em 25/04/06.

COMPANHIA DE TECNOLOGIA DE SANEAMENTO AMBIENTAL. (CETESB). 2005. Variáveis de qualidade das águas. Disponível em http://www.cetesb.sp.gov. br/Agua/rios/variaveis. Acesso em 25/10/2005.

CONSELHO NACIONAL DO MEIO AMBIENTE. (CONAMA). 2006. Resolução $n^{\circ} 357$, de 17 de março de 2005. Disponível em http://www.mma.gov.br/port/conama/legiano. Acesso em 26/04/2006.
Conceição F.T. \& Bonotto D.M. 2002. Relações hidroquímicas aplicadas na avaliação da qualidade da água e diagnóstico ambiental na bacia do Rio Corumbataí (SP). Geochim. Brasil., 16(1):1-21.

Conceição F.T. \& Bonotto D.M. 2004. Weathering rates and anthropogenic influences in a sedimentary basin, São Paulo State, Brazil. Applied Geochemistry, 19(4):575591.

Conceição F.T., Sardinha D.S., Souza A.D.G., Bonotto D.M. 2007. Hydrochemical Relationships at Meio Stream Watershed, São Paulo State, Brazil. Revista Brasileira de Geociências, 37(2):389-400.

Espíndola E.L.G., Silva J.S.V., Marinelli C.E., Abdon M.M. 2000. A Bacia Hidrográfica do Rio Monjolinho: uma abordagem ecossistêmica e a visão interdisciplinar. São Carlos, Editora Rima, 188p.

Esteves F.A. 1988. Fundamentos de Limnologia. Rio de Janeiro: Editora Interciência, 602p.

Garrels R.M. \& Mackenzie F.T. 1967. Origin of the chemical composition of some springs and lakes. In: Equilibrium concepts in natural waters systems. Am. Chem. Soc., Advances in Chemistry Series, 67:222-242.

Godoy A.M. 1989. Caracterização faciológica, petrográfica e geoquímica dos maciços Sorocaba e São Francisco - SP. Tese de Doutoramento, Instituto de Geociências, USP, São Paulo, 221p.

Godoy A.M. \& Figueiredo M.C.H. 1991. Caracterização fa- 
ciológica e petrográfica do Maciço Granitóide Sorocaba (SP). In: SBGeo, Simpósio de Geologia do Sudeste, São Paulo, Anais, 1:131-138.

Godoy A.M., Oliveira M.A.F., Hackspacher P.C. 1996a. Geoquímica das rochas granitóides da Folha São Roque. Revista Geociências, 15:67-88.

Godoy A.M., Hackspacher P.C., Oliveira M.A.F. 1996 b. Geologia da região de Sorocaba. Revista Geociências, 15:89-110.

Grasby S.E. \& Hutcheon I. 2000. Chemical dynamics and weathering rates of a carbonate basin Bow River, southern Alberta. Applied Geochemistry, 15:67-77.

Hach. 1992. Water Analysis Handbook. $2^{\circ}$ ed., Colorado, Hach Company, Loveland, USA, 831p.

Hackspacher P.C., Oliveira M.A.F. de, Godoy A.M. 1991. Controle do Nível Metamórfico e da Disposição dos Corpos Granitóides pela Tectônica Dn+3/Transcorrente na Folha Cabreúva. In: SBGeo, Simpósio de Geologia do Sudeste, São Paulo, Anais, 1:151-154.

Hermes L.C. \& Silva A. de S. 2004. Avaliação da qualidade das águas: manual prático. Brasília: Embrapa Informação Tecnológica, 55p.

INSTITUTO DE PESQUISA TECNOLÓGICA DO ESTADO DE SÃO PAULO (IPT). 2005. Relatório Técnico $n^{\circ}$ 80 401- 205. Atualização do relatório de situação dos recursos hídricos da Bacia do Sorocaba e Médio Tietê (Relatório Zero) como subsídio á elaboração do Plano de Bacia. São Paulo, 420p.

Lara L.B.L.S., Artaxo P., Martinelli L.A., Victoria R.L., Camargo P.B., Krusche A., Ayers G.P., Ferraz E.S.B., Ballester M.V. 2001. Chemical composition of rainwater and anthropogenic influences in the Piracicaba River basin, Southeast Brazil. Atmospheric Environment, 35:49374945.

Martini I.P. \& Chesworth W. 1992. Weathering, soils and paleosols. Amsterdam, Elsevier Science Publications, $618 \mathrm{p}$.

Meybeck M., Friedrich G., Thomas R., Chapman D. 1996. In: Chapman D. (ed.) Water quality assessments. London: UNESCO, WHO, UNEP, p. 241-320.

Moreira-Nordemann L.M. 1980. Use of ${ }^{234} \mathrm{U}^{238} \mathrm{U}$ disequilibrium in measuring chemical weathering rate of rocks. Geochimica et Cosmochimica Acta, 44:103-108.

Moreira-Nordemann L.M. 1984. Salinity and weathering rate of rocks in a semi-arid region. Journal of Hydrology, 71:131-147.

Motta S. 1997. Introdução a Engenharia Ambiental. Rio de Janeiro, ABES, 292p.

Négrel P. \& Roy S. 1998. Chemistry of rainwater in the Massif Central (France): a strontium isotope and major element study. Applied Geochemistry, 13:941-952.

Odum E.P. 1988. Ecologia. Rio de Janeiro, Editora Guanabara, $433 p$.

Pedro G. \& Sieffermann G. 1979. Weathering of rocks and formation of soils. Review in Modern Problems of Geo- chemistry. UNESCO, p. 39-55.

Piper A.M. 1944. A graphic procedure in the geochemical interpretation of water-analyses. Trans. Amer. Geophysical Union, 25:914-928.

Porto F.A. 1991. Estabelecimento dos parâmetros de controle da poluição. In: Porto S.M., Cleary R.W., Coimbra R.M, Eiger S., Luca S.J., Nogueira V.P.O., Porto F.A. (ed.) Hidrologia Ambiental. São Paulo, EDUSP, p. 375-390.

Sanusi A., Wortham H., Millet M., Mirabel P. 1996. Chemical composition of rainwater in eastern France. Atmospheric Environment, 30:59-71.

Sardinha D.S 2008. Sardinha D.S. 2008. Avaliação do intemperismo químico e influências antropogênicas na Bacia do Alto Sorocaba (SP). Dissertação de mestrado, Instituto de Geociências e Ciências Exatas, Universidade Estadual Paulista, 103p.

Souza A.D.G. \& Tundisi J.G. 2000. Hidrogeochemical comparative study of the Jaú and Jacaré-Guaçu river watersheds, São Paulo, Brazil. Revista Brasileira de Biologia, 60(4):563-570.

Souza A.D.G. \& Tundisi J.G. 2003. Water quality in watershed of the Jaboatão River (Pernambuco, Brazil): a case study. Brazilian Archives of Biology and Technology, 46(4):711-721.

Standard Methods. 1999. Standard methods for the examination of water and wastewater. $20^{\circ} \mathrm{ed}$., Washington, American Public Health Association, 663p.

Toledo M.C.M., Oliveira S.M.B., Melfi A. 2000. Intemperismo e formação do solo. In: Teixeira W., Toledo M.C.M., Fairchild T.R., Taioli F. (org.) Decifrando a Terra. Oficina de textos, São Paulo, p. 139-166.

Tundisi J.G., Matsumura-Tundisi T., Arantes Junior J.D., Tundisi J.E.M., Manzini N.F.I., Ducrot R. 2004. The response of Carlos Botelho (Lobo, Broa) reservoir to the passage of cold fronts as reflected by physical, chemical, and biological variables. Braz. J. Biol., 64(1):177-186.

Tundisi J.G. 2005. Água no Século XXI: Enfrentando a Escassez. $2^{\circ}$ ed., São Carlos, Editora Rima, 248p.

Tundisi J.G., Matsumura-Tundisi T., Abe D.S., Rocha O., Starling F. 2006. Limnologia de águas interiores: conservação e recuperação de ecossistemas aquáticos. In: Rebouças A.C., Braga J.B., Tundisi J.G. (org.) Águas Doces no Brasil: capital ecológico uso e conservação. 3 ed., São Paulo, Escrituras editora, p. 203-240.

Wetzel R.G. 1983. Limnology. Philadelphia: Saunders College, $767 p$.

White A.F. \& Blum A.E. 1995. Effects of climate on chemical weathering in watersheds. Geochim. Cosmochim. Acta, 59:1729-1747.

Manuscrito ID 11737

Submetido em 10 de julho de 2008 Aceito em 17 de dezembro de 2008 Sistema eletrônico de submissão 